\title{
Predicting the impact of drainage ditches upon hydrology and sediment loads using KINEROS 2 model: A case study in Ontario
}

\author{
Anand K. Gupta ${ }^{1 *}$, Ramesh P. Rudra ${ }^{1}$, Bahram Gharabaghi ${ }^{1}$, Prasad Daggupati ${ }^{1}$, Pradeep K. Goel ${ }^{2}$ and Rituraj Shukla \\ ${ }^{1}$ School of Engineering, University of Guelph, Guelph, ON N1G 2W1 Canada \\ ${ }^{2}$ Ontario Ministry of the Environment and Climate Change, Etobicoke, ON M9P 3 V6 Canada \\ E-mail: rrudra@uoguelph.ca
}

\begin{abstract}
Hydrologic models are calibrated and validated with an existing drainage network/drainage pattern (DNDP). However, in present times water could be routed through alternative DNDPs. The main objective of thispaper was to explore the performance of KINEROS 2 model in predicting streamflow and sediment yield in response to alterations in DNDP. Adopting the existing DNDP as an input, the model was calibrated for three events (18 April 2013, 12 June 2012, and 12 June 2013) and validated for two events (12 April 2014, and 30 August 2013) for flow at the watershed outlet. Further, the model was calibrated for eight events and validated for seven events for sediment content at the watershed outlet. Thereafter, the model was driven with a modified DNDP, and its response upon peak flow, direct runoff and sediment yield were investigated for two events (12 April 2014 and 18 April 2013) and a synthetic design storm (2-year-24 hour) at a sub-basin outlet (GUL_RSD). Three DNDPs: DNDP_M (road-side ditches with the same Manning's n), DNDP $\overline{M V}$ (road-side ditches lined with medium vegetation), and DNDP_HV (road-side ditches lined with thick vegetation) were considered. KINEROS 2 results revealed that peak flow, direct runoff, and sediment yield increased by $47.36 \%, 31.39 \%$, and $26.96 \%$ respectively for 12 April 2014 event for DNDP_M. Similar results were obtained for 18 April 2013 and synthetic design storm events. However, when road-side ditches were lined with a thicker vegetation (DNDP_MV and DNDP_HV), a reduction in peak flow, direct runoff, and sediment yield was observed.
\end{abstract}

\section{RÉSUMÉ}

Les modèles hydrologiques sont étalonnés et validés au moyen de configurations de drainage ou de réseaux de drainage existants (DNDP). Toutefois, à un moment donné l'eau pourrait s'écouler à travers des DNDPs différentes. L'objectif principal de cette étude était d'explorer la performance du modèle KINEROS 2 pour prédire un écoulement et un rendement de sédimentation en réponse à des changements de DNDPs. En considérant la DNDP existante comme donnée entrante, le modèle a été étalonné à l'aide de trois évènements ( 18 avril 2013, 12 juin 2012 et 12 juin 2013) et validé avec deux évènements (12 avril 2014 et 30 août 2013) pour évaluer l'écoulement à la sortie du bassin versant. De plus, le modèle a été étalonné à l'aide de huit évènements et validé avec sept évènements pour évaluer le contenu en sédiments à la sortie du bassin versant. Par conséquent, le modèle était attribuable à un DNDP modifié, et sa réponse après l'écoulement de pointe, le ruissellement direct et la production de sédiments ont été étudiés pour deux évènements (12 avril 2014 et 18 avril 2013) ainsi qu'avec un évènement pluvieux synthétique $(2$ ans $-24 \mathrm{~h})$ à la sortie d'un sous-bassin (GUL_RDS). Trois DNDPs : DNDP_M (fossés de route avec le même $\mathrm{n}$ de Manning), DNDP_MV (fossés de route recouverts d'une végétation moyenne) et DNDP_HV (fossés de route avec une végétation dense) ont été considérées. Les résultats obtenus avec le KINEROS 2 ont révélé que l'écoulement de pointe, le ruissellement direct et la production de sédiments augmentaient de $47,36 \%, 31,39 \%$ et $26,96 \%$ respectivement pour l'évènement du 12 avril 2014 pour le DNDP_M. Des résultats semblables ont été obtenus pour le 18 avril $2 \overline{0} 13$ et les évènements pluvieux synthétiques. Toutefois, lorsque les fossés de route étaient couverts avec une végétation abondante (DNDP_MV et DNDP_HV), une réduction de l'écoulement de pointe, du ruissellement direct et de la production de sédiments était observée.

\section{KEYWORDS}

Drainage network, modeling, KINEROS 2, watershed.

\section{MOTS CLÉS}

réseau de drainage, modélisation, KINEROS 2, bassin.

\section{CITATION}

Gupta, A.K., R.P. Rudra, B. Gharabaghi, P. Daggupati, P.K. Goel and R. Shukla. 2018. Predicting the impact of drainage ditches upon hydrology and sediment loads using KINEROS 2 model: A case study in Ontario. Canadian Biosystems Engineering/Le génie des biosystèmes au Canada 60: 1.1-1.15. https://doi.org/10.7451/CBE.2018.60.1.1 


\section{INTRODUCTION}

Agricultural runoff and subsurface drain effluents have a momentous impact upon the hydrology and water quality of a watershed (Sloan et al. 2017; Moriasi et al. 2012). Therefore, an appropriate understanding of the direct water routing scheme, across the watershed is of pivotal importance. Moreover, state-of-the-art agricultural drainage techniques have extensively modified the landscape topography at the watersheds-scale through the development of artificial canal networks

(Soana et al. 2017). These modest watercourses, whether natural or artificial, act as interfaces amidst agricultural lands and draining rivers and streams (Soana et al. 2017). Such canals are symbolized by numerous interaction amidst water, sediment and vegetation (Marion et al. 2014; Pinay et al. 2015). These watercourses are sometimes also referred to as "agricultural drainage ditches". Therefore, agricultural drainage ditches act as a water management practice employed to commute water (direct runoff and tile-fed drainage effluents) from agricultural fields to receiving ditches (Ahiablame et al. 2010; Smith and Pappas, 2007).

Agricultural drainage ditches essentially act as $1^{\text {st }}$ or $2^{\text {nd }}$ order streams which provide a linkage amidst agricultural farmlands and draining water bodies (Ahiablame et al. 2010; Smith and Pappas, 2007). In the $21^{\text {st }}$ century, issues concerning the transport of nutrients through agricultural drainage ditches to receiving ecosystems have been addressed by a plethora of researchers (Gentry et al. 2007; Kleinman et al. 2007; Smith et al. 2005; Strock et al. 2007). For instance, Alexander (Alexander et al., 2008) asserted that rural watersheds in midwest U.S are dominant cause for nitrogen $(\mathrm{N})$ and phosphorous $(\mathrm{P})$ transport in the Gulf of Mexico. Ahiablame et al. $(2010 ; 2011)$ reported nutrient uptake by benthic sediments in managed agricultural drainage ditches and later they found its potential impact on the quality of downstream waters in Indiana region. In another study in Italy, (Soana et al. 2017) studied the nitrogen mitigating efficiency of ditches nourished by spring water which is polluted by $\mathrm{NO}_{3}^{-}$with and without emergent vegetation. Further, (Iseyemi et al., 2016) investigated the nutrient removal efficiency of mowed and unmowed agricultural drainage ditches during an experimental study. The authors reported no significant difference between the nutrient removal capacity for the two treatments.

Additionally, based upon their construction scheme and location, agricultural drainage ditches could also be classified into road-side ditches (RSD) if directly feeding runoff effluents (tile flow and runoff) collected from agricultural fields to downstream watercourses. Also, RSD are always constructed along the periphery of roads. Therefore, any alteration in the DNDP where water is routed through RSD is expected to increase the quantity of water and sediment routed downstream of a watershed since it provides a short pathway for routing water. Water which would be have been routed through elongated gullies and creeks under normal drainage pattern would now be routed directly through short RSD to downstream watercourses. Therefore, increase in peak flow and runoff volume is expected under the new drainage pattern. While many studies have investigated impacts of agricultural drainage ditches on hydrology and water quality, the process is understudied for RSD (Birgand et al. 2007; Cuo et al. 2006; Needelman et al. 2007).

RSD analyzed in previous studies have revealed them to be a conduit for E. coli and sediments under both agricultural and forested settings (Falbo et al. 2013). Smith (2009) found phosphorus uptake lengths between 40 and $1900 \mathrm{~m}$ within agricultural drainage ditches in Northeast Indiana. These values generally increased with watershed size for a single drainage ditch due to SP uptakes proportion. They also exposed SP uptake rates (U) to be greater at smaller sites. However, due to difficulty in monitoring runoff and sediment losses through RSD, there is a paucity of published research in this topic.

Additionally, field scrutinization in agriculture, through experimentation, is largely empirical and sitespecific (Ma et al. 2001). On the contrary, computer models (viz., SWATDRAIN, SWAT, AGNPS etc.), could be employed efficiently and cost-effectively for simulating the biogeochemical processes of agro-ecosystems at different scales (Golmohammadi et al. 2016). However, due to the complexity in simulating flow and sediments through RSD, few researchers have tried to model the influence of RSD in transmuting flow and sediment transport through the aid of hydrological models. Buchanan et al. (2013) used the SDDH-VSA (Buchanan et al. 2011) model and concluded that RSD substantially modifies the watershed morphometry and natural flow pathways, thereby expediting the transport of agricultural pollutants, that would have otherwise mitigated considerably under natural degradation processes.

In Canada, (Surfleet et al. 2010) used the DHSVM model along with the generalized likelihood uncertainty estimation procedure in two streams and 11 RSD. The sensitivity of parameters and the range of the sensitivity varied across simulations for flow in the ditches and stream. Further, water routed through man-made agricultural drainage ditches or RSD significantly alters the DNDP of a watershed. Therefore, investigating the impacts of DNDP changes on hydrology or water quality, which are either projections or purely scenario analysis, need to be assessed through watershed modeling. Hydrologic conditions are of paramount importance while setting up a model. For example, Borah and Bera (2004) stated that a continuous modeling approach is less accurate for modeling stream flows, which are characterized by impulsive storm events. Therefore event-based models would perform better in simulating storm events, including storms that generate runoff (Borah et al. 2007). Additionally, sediment and nutrient transported along with direct runoff are predominantly influenced by the intensity of the storm. Henceforth; event-based modeling is deemed more 
appropriate for simulating $\mathrm{RSD}$ as compared to a continuous approach.

KINEROS 2 is an event-based, distributed and dynamic model that predicts direct runoff, erosion losses, infiltration amount, and interception depth from the catchments, produced by predominantly overland flow (Smith et al. 1999; Semmens et al. 2007). Also, the model operates on a cascade modeling approach. Given the robustness of the model, it could be used for simulating flow through RSD. Therefore, the objective of this paper is to evaluate the performance of the KINEROS 2 model in predicting impacts of DNDP changes upon water quantity and sediment yield in a watershed in Ontario, Canada, specifically if water is routed through an alternate drainage ditch like RSD.

The following two important questions associated with RSD modeling with KINEROS 2 model were addressed in this paper:

- What would be the impact of a routing flow through RSD upon downstream flow and sediment yield?

- What would be the impact of lining the RSD with different vegetation upon downstream flow and sediment yield?

\section{MATERIALS AND METHODS \\ KINEROS 2 model}

KINEROS 2 (K2) model is an advanced version of KINEROS model (Woolhiser et al. 1990). K2 is a physically based, distributed model operating on an event basis capable of simulating direct runoff, erosion, infiltration, and interception depth from watersheds (Smith et al. 1999). Also, watersheds and their sub-basins are represented by cascades of overland flow planes (OFP), channels and impoundments in the model. OFP can be split into several constituents with distinct slopes, roughness, soils, etc. Further, contiguous planes can have different widths in the model (Semmens et al. 2007). Moreover, the $\mathrm{K} 2$ intercalates micro-topography in the simulation. K2 may be used to determine the effects of various artificial features, such as urban development, small detention reservoirs, or lined channels on flood hydrographs and sediment yield. Upon rainfall rate's exceedance of the infiltration capacity, overland flow is initiated. K2 could be used to analyze the impact of several design structures and artificial scenario's, such as small reservoirs, urban development, or lining channels with different vegetation upon flood hydrographs and sedimentographs. Upon rainfall rate's exceedance of the infiltration capacity, overland flow is initiated. Further, the K2 model assumes one-dimensional flow in each plane and solves the continuity equation with a kinematic wave approximation to compute flow in planes and channels as shown in equation (1).

$$
\frac{\partial h}{\partial t}+\alpha m h^{m-1} \frac{\partial h}{\partial x}=q_{L}(x, t)
$$

where

$\mathrm{h}=$ flow depth,

$\mathrm{t}=$ time,

$\mathrm{x}=$ the distance along the slope direction,
$q_{L}=$ lateral inflow rate, and

$\alpha$ and $\mathrm{m}=$ parameters related to slope, direct roughness, and flow regime. Unit flow discharge $(\mathrm{q})$ is correlated to flow depth with the expression $\mathrm{Q}=\alpha h^{m}$.

Also, the mass balance equation is used to compute sediment transport in planes and channels (Eq. 2).

$$
\frac{\partial(A C)}{\partial t}+\frac{\partial(Q C)}{\partial x}-e(x, t)=q_{s}(x, t)
$$

where

$\mathrm{A}=$ cross-sectional area of the channel

$\mathrm{C}=$ volumetric sediment concentration,

$\mathrm{Q}=$ channel discharge,

$\mathrm{e}=$ sediment erosion rate, and

$\mathrm{q}_{\mathrm{s}}=$ rate of lateral sediment inflow for channels.

\section{Study area}

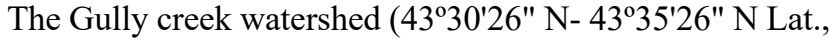
$81^{\circ} 37^{\prime} 42.19^{\prime \prime} \mathrm{W}-81^{\circ} 39^{\prime} 51.9^{\prime \prime} \mathrm{W}$ Long) draining into Lake Huron, Ontario Canada; along with one of its sub-basin outlet (GUL_RSD) is selected for this study (Fig. 1). Gully Creek watershed encompasses an area of 1056.84 hectares. The landscape is characterized by undulating terrain with a maximum elevation of $281 \mathrm{~m}$ and minimum elevation of $217 \mathrm{~m}$. Further, the GUL_RSD outlet drains a sub-basin comprising an exhaustive network of RSD. These ditches, if operational under a future drainage scenario for routing water, would ultimately drain at the GUL_RSD outlet. Therefore, GUL_RSD is considered for comparison analysis amongst various scenarios for this study (Fig. 1).

Nearly $60 \%$ of the precipitation occurs as rainfall from April to October while the remaining as snow/rainfall during the five winter months from November to March. The average annual precipitation is $1,055 \mathrm{~mm}$ over 2001 2011 with a standard deviation of $165 \mathrm{~mm}$ (Liu 2013). Upper reaches of the watershed are dominated by clay loam soil while the lower reaches are mostly sandy loam. The name and areal extent of each soil type are presented in Table 1 . Nearly $70 \%$ of the watershed is agricultural with corn, soybean and winter wheat being the primarily grown crops (Fig. 2). Remaining $25 \%$ of the watershed is under natural vegetation, including trees, shrubs, and grasses (Golmohammadi et al. 2017). Naturally vegetated areas primarily buffer along the main channel.

\section{Base flow separation}

The K2 could be used to simulate direct runoff and erosion for moderate-size watersheds on an event basis (Smith et al. 1995). Therefore, base flow is removed from the total streamflow at the watershed outlet (GULGUL 5 station) for competent calibration and validation of events. Direct runoff and base flow unify to compound total stream flow.

Table 1. Name and extent of each soil type in the Gully Creek watershed.

\begin{tabular}{clcc}
\hline Soil code & Soil type & Area (ha) & Area (\%) \\
\hline ZAL & Bottom Land & 84.57 & 8.08 \\
PTH & Perth Clay & 101.06 & 9.66 \\
HUO & Huron Clay & 797.11 & 76.21 \\
BKN & Brookston & 63.26 & 6.05 \\
\hline
\end{tabular}




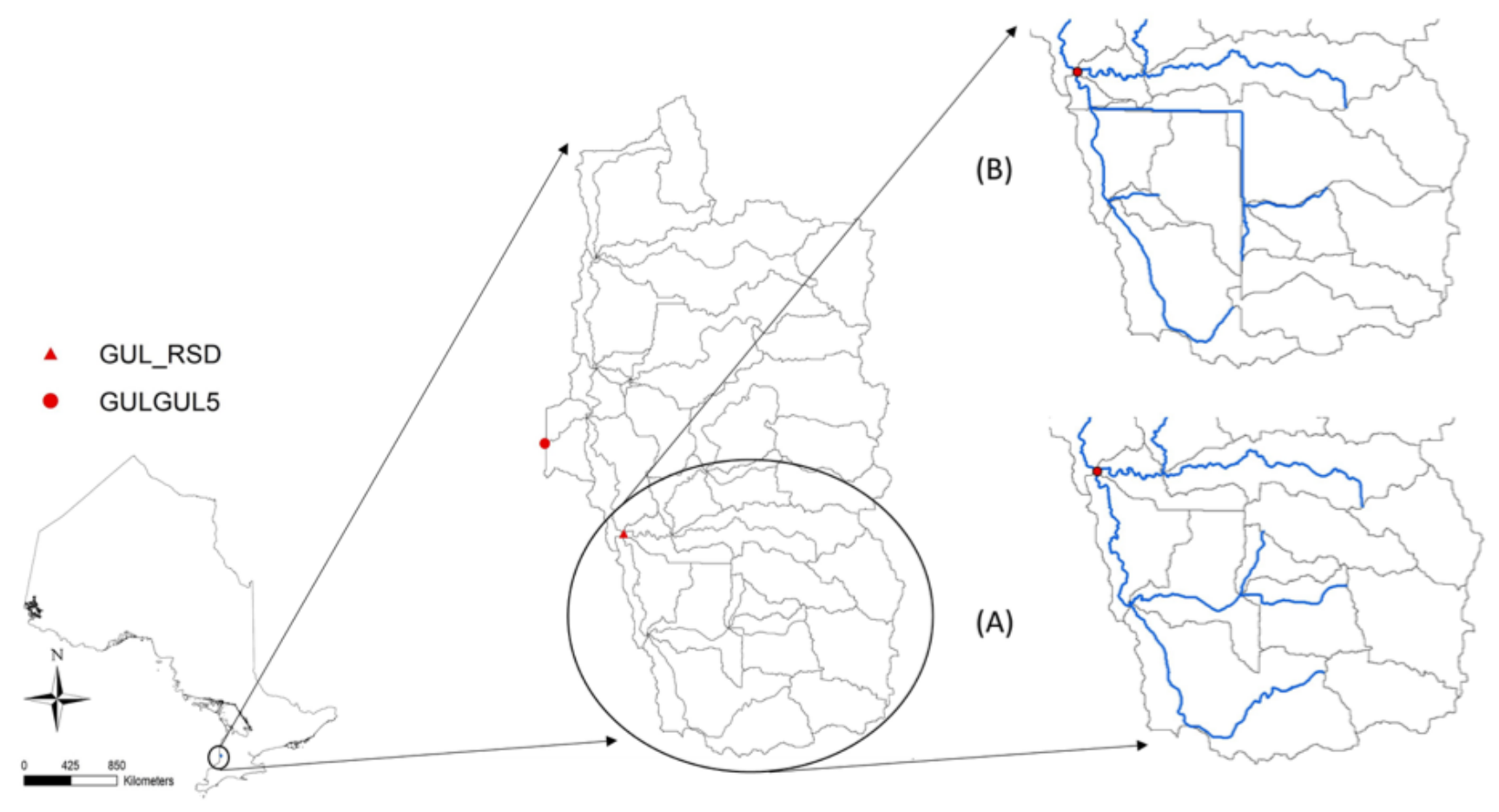

Fig. 1. Location of Gully Creek watershed in Ontario, Canada for (A) natural and (B) modified DNDP.

While direct runoff is a fast contributor to stream flow, base flow is a slow contributor to streamflow (Kalin and Hantush, 2006b). WHAT software developed at Purdue University

(https://engineering.purdue.edu/mapserve/WHAT/) was used to separate base flow from observed flow in this study. The methodology of the WHAT program is described by Kyoung et al. (2005). This methodology is based upon signal analysis and processing which splits high frequency signals (associated with direct runoff) from low frequency signals (associated with base flow) (Eckhardt and Arnold 2001; Lyne and Hollick 1979).

\section{Sediment load estimation}

Sediment loads are considered as a parameter for assessing water quality in this study. Therefore, sediment loads for the selected rainfall events considered need to be compared with the K2 simulated sediment loads for calibration and validation. Henceforth, sediment loads should have an identical temporal resolution with observed streamflow data. Further observed streamflow data used during this study was available for every 15 minutes; from which direct runoff was separated and events prepared accordingly. However, due to collection and analysis costs involved, observed sediment loads were available for only some grab samples. Henceforth; sediment loads for these grab samples were extrapolated to procure observed sediment load for each event. Thereafter, observed sediment load for each event was compared with $\mathrm{K} 2$ simulated sediment load for that particular event. To extrapolate sediment load of the grab samples on an event basis, LOAD ESTimator (LOADEST) a web-based tool (https://engineering.purdue.edu/mapserve/LOADEST/) was employed (Park et al. 2015; Runkel et al. 2004). The tool estimates monthly sediment loads using observed streamflow, observed sediment concentration data (for grab samples), and regression model coefficients.

There are eleven regression models in the LOADEST model. Further, three statistical methods: adjusted maximum likelihood estimation (AMLE), maximum likelihood estimation (MLE) and least absolute deviation (LAD) are used for calibrating its coefficients (Runkel et al. 2004). The AMLE method was used to compute monthly sediment loads. Further, the monthly sediment loads were extrapolated to procure sediment loads for each event based upon the month of the event and the duration of the storm event.

\section{Input data}

Geospatial data used to setup the K2 model included a digital elevation model, DEM (5 $\mathrm{m}$ resolution), soil, land use, and streamflow network (Fig. 2). The data layers were obtained from Ontario Ministry of Agriculture, Food, and Rural Affairs (OMAFRA), Ontario Ministry of Natural Resources and Forestry (OMNRF), and the Ausable Bayfield Conservation Authority (ABCA). Precipitation data (April 2013 to May 2014) for K2 was obtained from a weather station installed within the watershed which had 


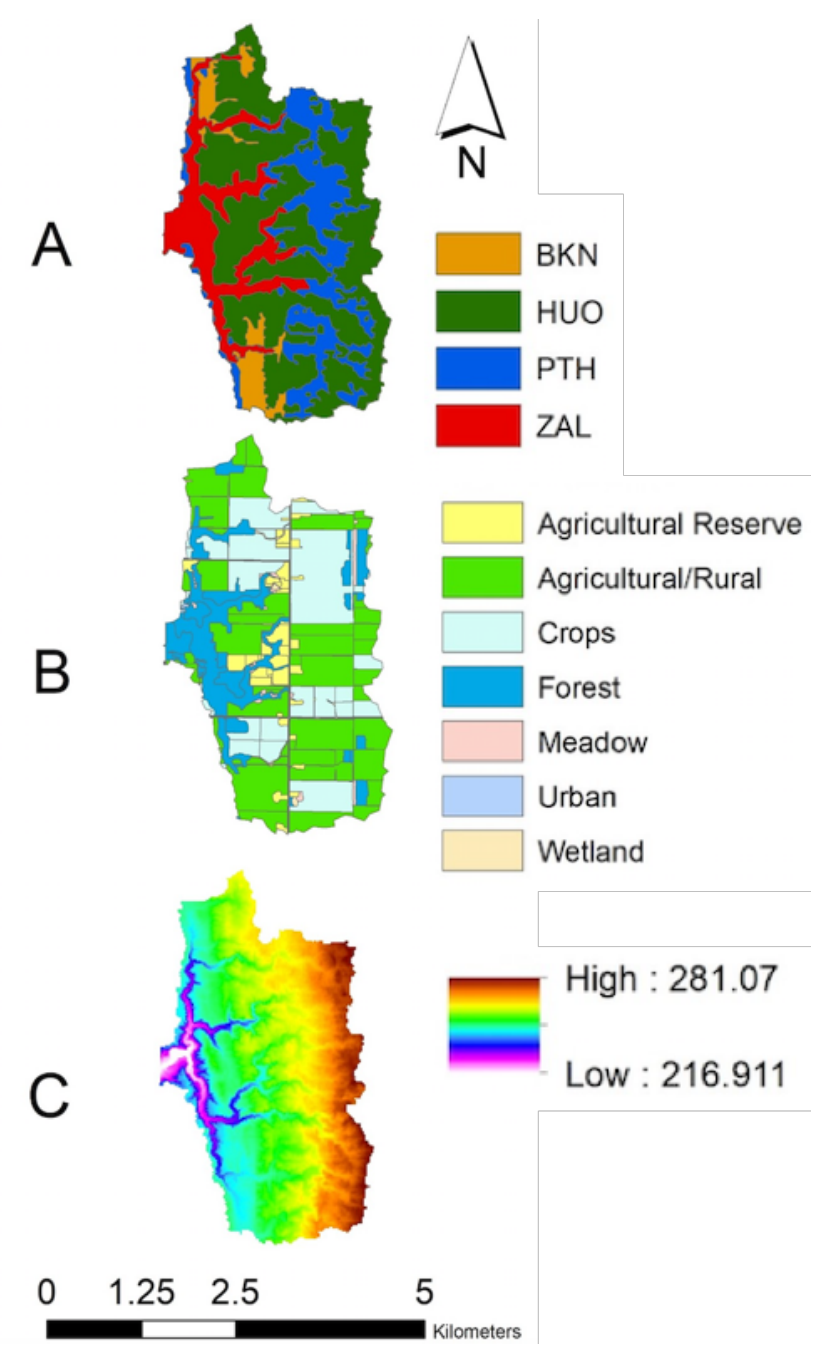

Fig. 2. (A) Soil, (B) Landuse, and (C) DEM of the Gully creek watershed.

been established as a part of Watershed Based BMP Evaluation project by Yang et al. (2013) initiated in April 2011.

Two different drainage network patterns (natural and RSD) were used as input for creating two different models. The natural drainage pattern was the most representative dataset for the entire watershed and hence used to calibrate and validate the K2 model. Modified drainage network, which was specifically developed for this study (details are

Table 2. Calibrated KINEROS 2 parameters.

\begin{tabular}{lcl}
\hline Process & Parameter & \multicolumn{1}{c}{ Description } \\
\hline Flow & $\mathrm{K}_{\mathrm{s}}$ & Saturated hydraulic \\
Flow & $\mathrm{n}_{\mathrm{c}}$ & Channel's manning's roughness \\
Flow & $\mathrm{n}_{\mathrm{p}}$ & plane's \\
Flow & $\mathrm{S}_{\mathrm{i}}$ & Si is initial relative saturation \\
Flow & $\mathrm{G}$ & Effective capillary drive \\
Sediment & $\mathrm{d}_{50}$ & Median particle size diameter. \\
Sediment & $\lambda$ & pore size distribution index \\
Sediment & $\phi$ & porosity \\
\hline
\end{tabular}

given, Fig. 1), was used as input for the second model (modified DNDP) to perform post-validation for the events.

\section{Model calibration and validation}

Prior to model calibration, detailed review of the literature was conducted to determine parameters which are sensitive to the model (Kalin and Hantush, 2006a; Memarian et al., 2013). Consequently, a sensitivity analysis was performed to identify the most sensitive parameters (see Table 2). Henceforth only the identified sensitive parameters (Table 2) were used for model calibration. Further, manual calibration was performed in this study, based upon previous experience with the K2 model (i.e. expert knowledge) (see, for example, Kalin and Hantush, 2006a; Memarian et al. 2013; Nguyen et al. 2016; Acde et al. 2017). Also, calibration and validation of the model were performed using a multiplier approach. Quantitative and qualitative measures were coupled together during the calibration of the model. A conscious effort was made to maximize the statistics which demonstrate the performance of the model (more on these below) on an event basis.

Statistics computed for estimating the efficiency of the model in simulating flow were Nash-Sutcliffe coefficient $\left(\mathrm{E}_{\mathrm{NS}}\right)$, model bias (MB) and modified correlation coefficient ( $\mathrm{r}_{\mathrm{mod}}$ ) (Safari et al. 2012; Moriasi et al. 2015; Nash and Sutcliffe 1970) while coefficient of determination $\left(\mathrm{R}^{2}\right)$, Nash-Sutcliffe coefficient ( $\left.E_{N S}\right)$ were used to estimate the models performance in predicting sediment loads. A lower value for these statistical parameters indicates a poor prediction of the model. On the contrary, a higher value suggests a good prediction of the model. For assessing the size, shape, and volume of simulated hydrographs/ sedimentographs, an aggregated measure (AM) was calculated using equation (3).

$$
\mathrm{AM}=\frac{r_{m o d}+E_{N S}+(1-|M B|)}{3}
$$

where

$\mathrm{E}_{\mathrm{NS}}=$ Nash-Sutcliffe coefficient,

$\mathrm{MB}=$ model bias,

$r_{\text {mod }}=$ modified correlation coefficient .

Model validation was performed based on the parameters determined during the calibration of the model. For flow, we investigated the peak flow and total direct runoff of the events to make sure that the model is performing well in predicting the hydrology of the watershed. The flow component of the K2 model was calibrated for three events (18 April 2013, 12 June 2012, and 12 June 2013) and validated for two events (12 April 2014 and 30 August 2013) respectively at the GULGUL 5 outlet (Table 3 ). Since sedimentographs for observed events were not available due to lack of grab samples $(n=280$ between April 2012 to June 2014), only a total sediment load could be estimated for the entire event using the methodology described in the earlier section. Therefore, eight events were used to calibrate $\mathrm{K} 2$ simulated sediment load with the observed sediment loads. Also, seven events were used to validate the sediment loads (Table 4). Value of parameters altered during the calibration process is shown in Table 5. Further, Nash-Sutcliffe coefficient ( $\left.\mathrm{E}_{\mathrm{NS}}\right)$ and coefficient of determination $\left(\mathrm{R}^{2}\right)$ were used to compute the model's efficiency in simulating sediment loads. 
Table 3. KINEROS-2 model parameters and outputs for calibration and validation events for flow.

\begin{tabular}{|c|c|c|c|c|c|c|c|c|c|c|}
\hline & Event date & $\begin{array}{l}\text { Precip } \\
\text { itation } \\
(\mathrm{mm})\end{array}$ & $\begin{array}{l}\text { Duration } \\
\text { (hrs) }\end{array}$ & $\mathrm{n}_{\text {channel }}$ & $\mathrm{n}_{\text {plane }}$ & $\begin{array}{l}\mathrm{K}_{\mathrm{s}} \\
(\mathrm{mm} / \mathrm{hr})\end{array}$ & $\begin{array}{l}Q_{\text {Peak }}^{\text {Observed }} \\
\left(\mathrm{m}^{3} / \mathrm{s}\right)\end{array}$ & $\begin{array}{l}\mathrm{Q}_{\text {Peak }}^{\text {Simulated }} \\
\left(\mathrm{m}^{3} / \mathrm{s}\right)\end{array}$ & $\begin{array}{c}\text { Direct } \\
\text { Runoff } \\
\text { (Observed) } \\
\left(\mathrm{m}^{3}\right)\end{array}$ & $\begin{array}{c}\text { Direct } \\
\text { Runoff } \\
\text { (Simulated) } \\
\left(\mathrm{m}^{3}\right)\end{array}$ \\
\hline & 2013-04-18 & 30.6 & 10 & 0.1 & 0.25 & 0.82 & 2.38 & 2.26 & 33389.94 & 22433.98 \\
\hline & 2012-06-12 & 18.2 & 2 & 0.1 & 0.25 & 0.82 & 0.34 & 0.46 & 4490.99 & 5378.02 \\
\hline \multirow[t]{2}{*}{ Calibration } & 2013-06-12 & 19.0 & 3 & 0.1 & 0.25 & 0.82 & 0.24 & 0.46 & 5561.99 & 5557.91 \\
\hline & 2014-04-12 & 27.4 & 7 & 0.1 & 0.25 & 0.82 & 1.79 & 1.94 & 35131.44 & 19658.35 \\
\hline Validation & $2013-08-30$ & 18.0 & 3 & 0.1 & 0.25 & 0.82 & 0.28 & 0.27 & 2803.73 & 2892.17 \\
\hline
\end{tabular}

\section{Post-validation}

The K2 model was calibrated and validated under the natural existing DNDP. Further, the model parameters adjusted during the calibration of the model were transferred to the model with modified DNDP (for RSD) during the post-validation phase. To accomplish the required task, modified DNDP was used as an input to K2 in place of the previously used DNDP_NDNDP_N for the Gully Creek watershed. While the calibration process is used to determine and adjust the sensitive parameters in order to bring model simulated flow values close to their observed counterparts, it is equally important to transfer these calibrated model parameters in a systematic way when the model is set up with a different DNDP. This was the case during post-validation of the $\mathrm{K} 2$ model, where DNDP_N was replaced by the modified DNDP.

For this purpose, calibrated model parameters were transferred according to the soil and landuse combinations for planes and channels (see Fig. 3). In other words, there was no new model calibration. The same parameter values obtained during the calibration period were used during the post-validation period, too. For example, effective capillary drive $\mathrm{G}$ was altered for different soil types (Table 5) and Manning's $n$ was changed for planes and channels. Further, the model was also run using the modified DNDP to visualize the differences in model simulations using various DNDP for two events (12 April 2014, and 18 April 2013). This was done to demonstrate the significance of draining flow through RSD in modeling. Further, various scenarios for the modified DNDP (road-side ditch) were considered for scenario analysis: DNDP_M (road-side ditches with the vegetation as DNDP_N), DNDP_MV (road-side ditches lined with medium vegetation), and DNDP_HV (road-side ditches lined with thick vegetation). Basically, Manning's n was changed for these scenario's. Thereafter model simulations for various DNDP scenarios were compared with the existing DNDP at the GUL_RSD outlet to demonstrate the performance of the model.

\section{RESULTS AND DISCUSSION}

\section{Calibration and validation}

Flow Calibration and validation were executed manually by comparing observed and $\mathrm{K} 2$ simulated direct runoff hydrographs. Model parameters such as effective capillary drive $\mathrm{G}$, pore size distribution index $\lambda$, Manning's $\mathrm{n}$ and porosity $\phi$ were adjusted during the calibration events which have considerable impact upon direct runoff and peak flow (Table 4 and 6).

Therefore, model parameters were manually manipulated for each overland flow plane (OFP) and each channel until peak flow and direct runoff simulated at the outlet channel of the K2 model (GULGUL 5) closely

Table 4. KINEROS-2 model parameters for calibration and validation events for sediment.

\begin{tabular}{|c|c|c|c|c|c|c|}
\hline & Event & Precipitation (mm) & Duration & Observed & KINEROS 2 & \\
\hline \multirow[t]{9}{*}{ Calibration } & $2012-10-14$ & 18.40 & 20 & 740 & 810 & $\mathrm{R}^{2}=0.93$ \\
\hline & 2013-09-20 & 24.80 & 5 & 270 & 1040 & $E_{N S}=0.81$ \\
\hline & 2013-04-18 & 30.60 & 10 & 19490 & 27230 & \\
\hline & 2014-04-12 & 27.39 & 7 & 12790 & 16320 & \\
\hline & 2013-08-01 & 59 & 15 & 19490 & 14180 & \\
\hline & 2013-06-16 & 14 & 6 & 300 & 1710 & \\
\hline & $2013-06-28$ & 15.80 & 8 & 320 & 2290 & \\
\hline & $2012-10-20$ & 15.80 & 15 & 1290 & 600 & \\
\hline & Average & & & 6840 & 8026 & \\
\hline \multirow[t]{7}{*}{ Validation } & 2012-11-12 & 16.40 & 9 & 910 & 1090 & $\mathrm{R}^{2}=0.79$ \\
\hline & 2014-04-29 & 22.40 & 9 & 12420 & 13510 & $E_{N S}=0.56$ \\
\hline & $2013-04-24$ & 20.20 & 21 & 20850 & 8600 & \\
\hline & 2013-08-30 & 18 & 3 & 4945 & 6280 & \\
\hline & $2012-06-12$ & 18.20 & 2 & 133 & 1010 & \\
\hline & 2013-06-12 & 19 & 3 & 530 & 1046 & \\
\hline & Average & & & 6630 & 5260 & \\
\hline
\end{tabular}




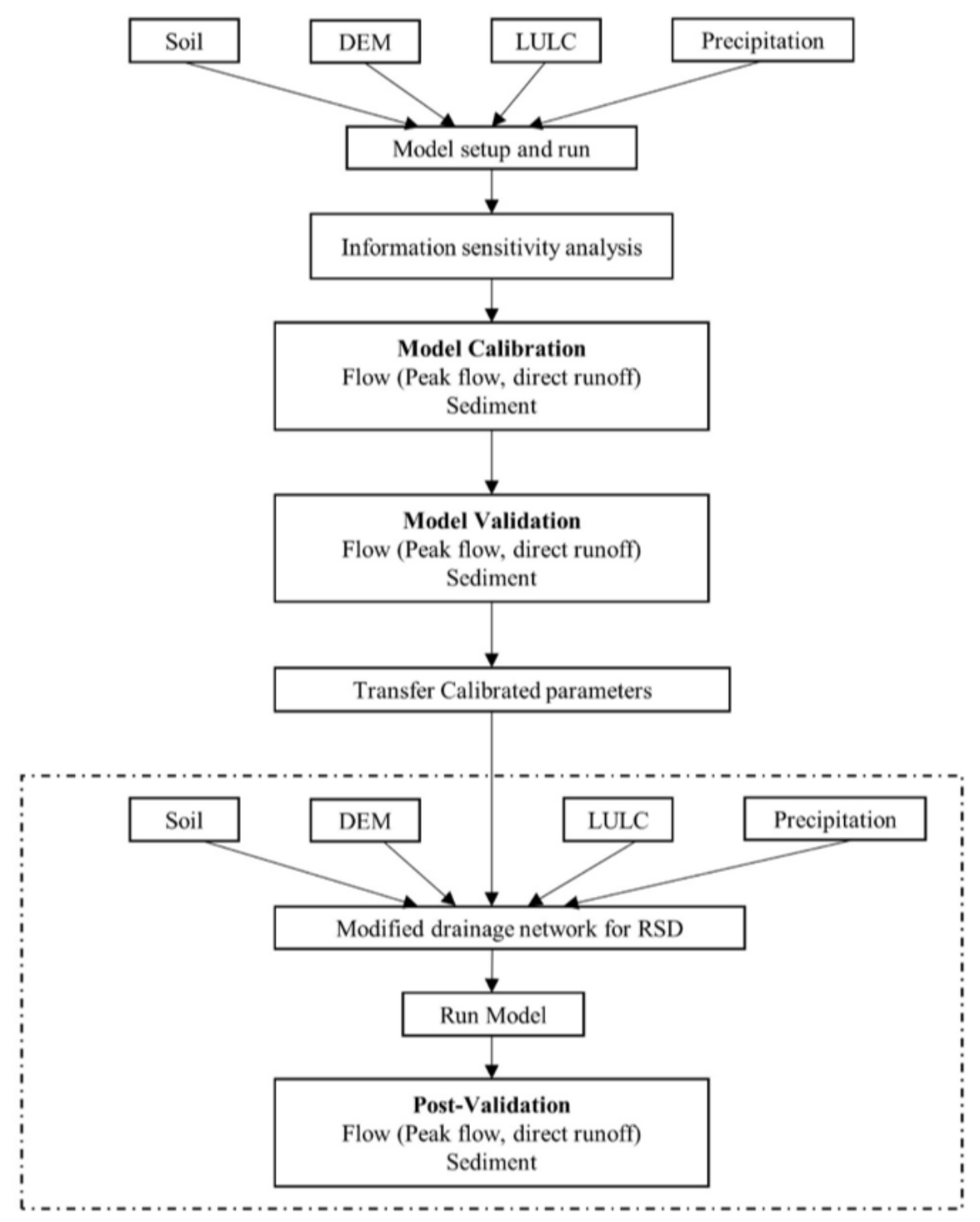

Table 5. Soil parameters calibrated during KINEROS-2 simulations.

\begin{tabular}{llcccc}
\hline Soil & Soil type & $\mathrm{G}(\mathrm{cm})$ & $\lambda$ & $\phi$ & $\mathrm{d}_{50}(\mu \mathrm{m})$ \\
\hline ZAL & Bottom Land & 31.14 & 0.21 & 0.53 & 1 \\
PTH & Perth Clay Loam & 40.04 & 0.18 & 0.45 & 1 \\
HUO & Huron Clay & 45.03 & 0.17 & 0.41 & 1 \\
BKN & Brookston Clay & 42.04 & 0.23 & 0.42 & 1 \\
\hline
\end{tabular}

Fig. 3. Flow chart presenting the methodology used in the study for model set up, calibration, validation, and post-validation.

Table 6. Model statistics for calibration and validation flow events.

\begin{tabular}{|c|c|c|c|c|c|}
\hline & \multicolumn{3}{|c|}{ Direct Runoff Simulation of Calibration Events } & \multicolumn{2}{|c|}{$\begin{array}{l}\text { Direct Runoff Simulation of } \\
\text { Validation Events }\end{array}$} \\
\hline Statistical fitting & 2013-04-18 & 2012-06-12 & 2013-06-12 & 2014-04-12 & $2013-08-30$ \\
\hline MB & -0.25 & 0.24 & -0.01 & -0.34 & 0.17 \\
\hline$r_{\text {mod }}$ & 0.89 & 0.57 & 0.68 & 0.9 & 0.76 \\
\hline $\mathrm{E}_{\mathrm{NS}}$ & 0.8 & 0.19 & 0.6 & 0.72 & 0.6 \\
\hline AM & 0.81 & 0.51 & 0.76 & 0.76 & 0.73 \\
\hline Goodness of fit & Good & Good & Good & Average & Below average \\
\hline Observed peak flow $\left(\mathrm{m}^{3} / \mathrm{s}\right)$ & 2.38 & 0.34 & 0.24 & 1.79 & 0.28 \\
\hline Simulated peak flow $\left(\mathrm{m}^{3} / \mathrm{s}\right)$ & 2.26 & 0.46 & 0.46 & 1.94 & 0.27 \\
\hline
\end{tabular}



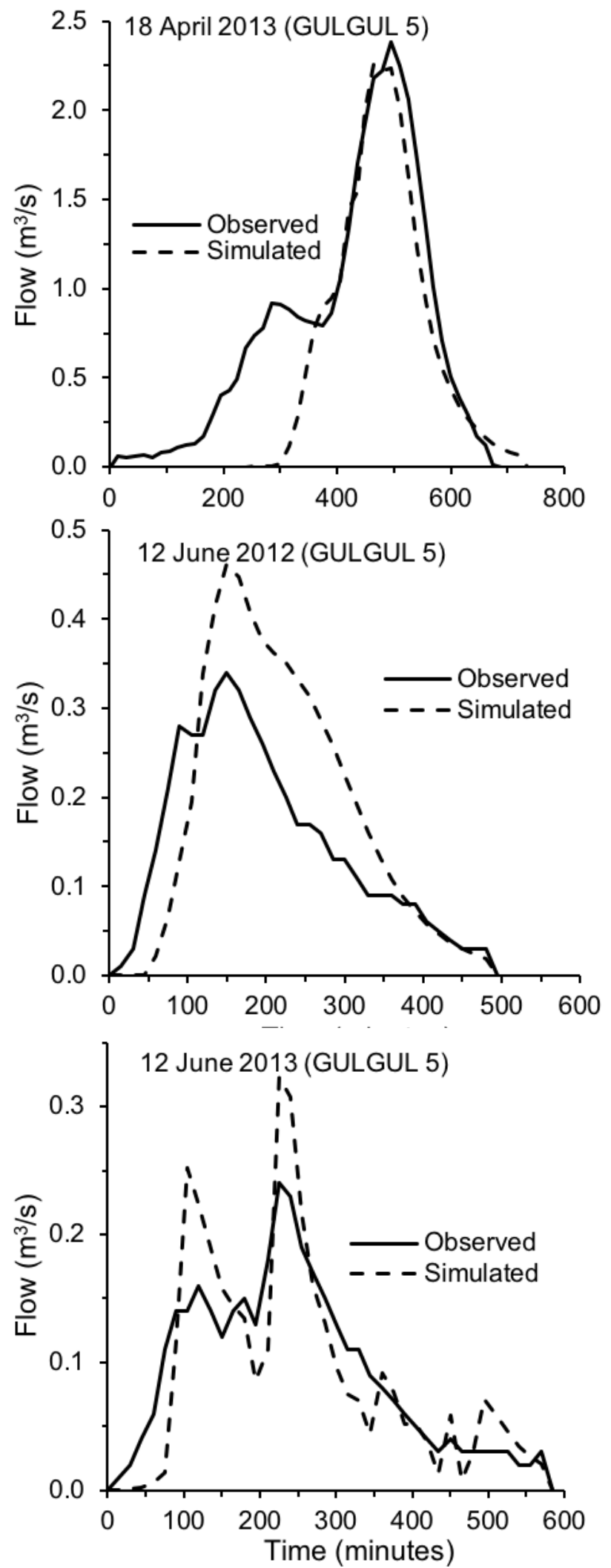

Fig. 4. Computed and observed hydrographs with KINEROS-2 for calibration events. matched the observed values. The logic behind altering parameters like Manning's $n$ for each plane and channel is that once a close agreement is reached between observed and modelled values for peak flow and direct runoff at the watershed outlet, the adjusted values for model parameters (manning's n, G, Ks etc.) would be realistic and match the real-world parameters for each plane and channel within the watershed. Hence, these parameters could be transferred to another model with similar conditions during post-validation.

Table 6 reveals the model statistics computed for the calibration and validation events respectively. K 2 model simulated values for peak flow and direct runoff were compared with their subsequent observed values during model calibration and validation respectively. Also, Table 6 reveals the observed and computed direct runoff and peak flow for calibration events. The model performs fairly well
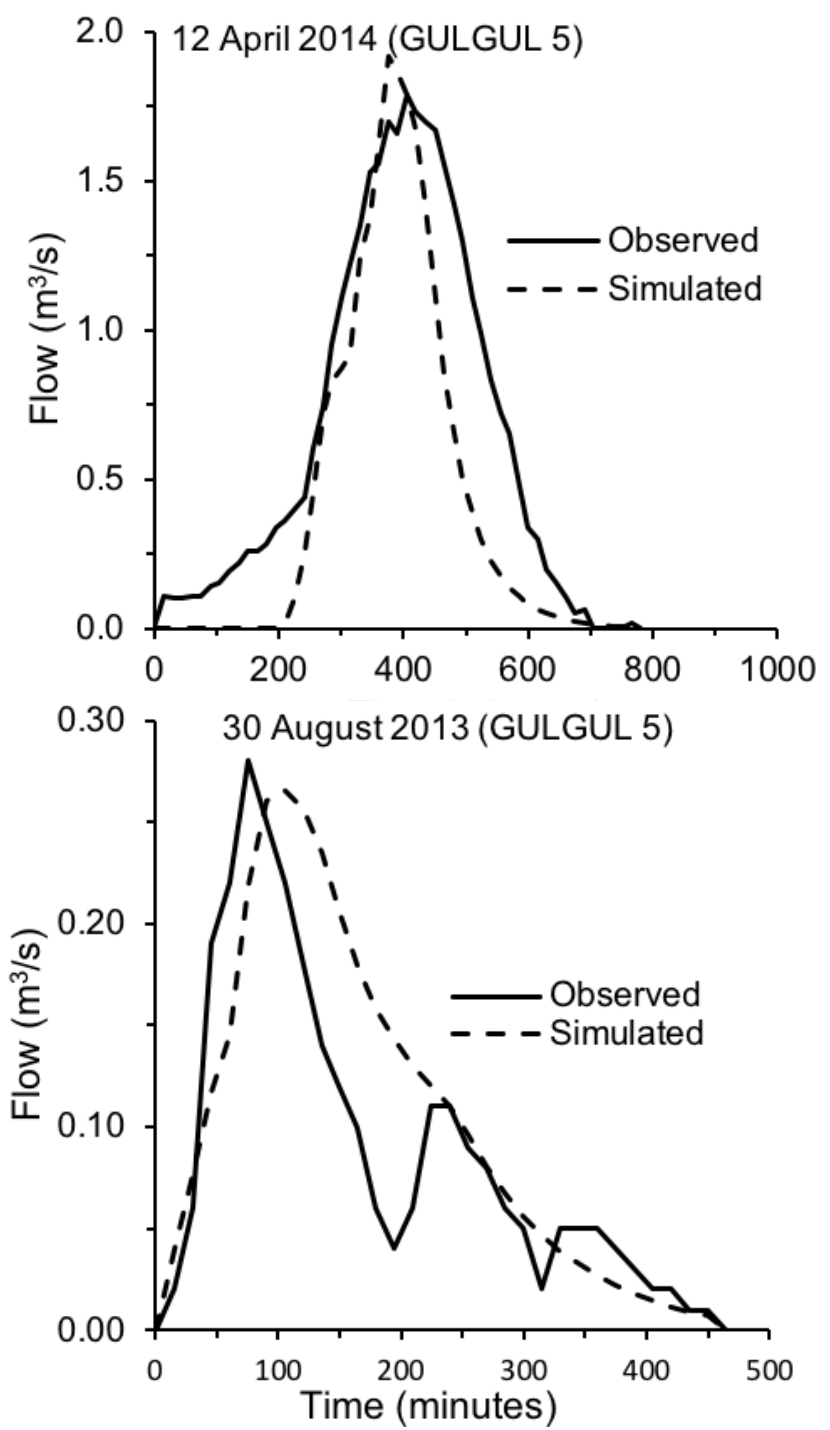

Fig. 5. Computed and observed hydrographs with KINEROS-2 for validation events. 
Table 7. Manning's n for various drainage network/drainage pattern (DNDP).

\begin{tabular}{|c|c|c|c|c|c|c|c|c|}
\hline & \multicolumn{3}{|c|}{ 2014-04-12 } & \multicolumn{5}{|c|}{ 2013-04-18 } \\
\hline & DNDP_N & $\begin{array}{c}\text { DNDP_M } \\
(\mathrm{n}=0.1)\end{array}$ & $\begin{array}{c}\text { DNDP_MV } \\
(\mathrm{n}=0.15)\end{array}$ & $\begin{array}{c}\text { DNDP_HV } \\
(\mathrm{n}=0.2)\end{array}$ & DNDP_N & $\begin{array}{c}\text { DNDP_M } \\
(\mathrm{n}=0.1)\end{array}$ & $\begin{array}{c}\text { DNDP_MV } \\
(\mathrm{n}=0.15)\end{array}$ & $\begin{array}{c}\text { DNDP_HV } \\
(\mathrm{n}=0.2)\end{array}$ \\
\hline$\overline{\mathrm{Q}_{\mathrm{P}}\left(\mathrm{m}^{3} / \mathrm{s}\right)}$ & 1.14 & 1.68 & 1.31 & 1.16 & 1.85 & 2.26 & 2.14 & 1.83 \\
\hline Runoff $\left(\mathrm{m}^{3}\right)$ & 8367.52 & 10994.35 & 9457.88 & 9093.03 & 13382.13 & 16010.77 & 14894.20 & 13590.06 \\
\hline Sediment load $(\mathrm{Kg})$ & 13283.20 & 16865.50 & 15785.50 & 14426.70 & 21774.67 & 25765.60 & 24678.60 & 22685.60 \\
\hline
\end{tabular}
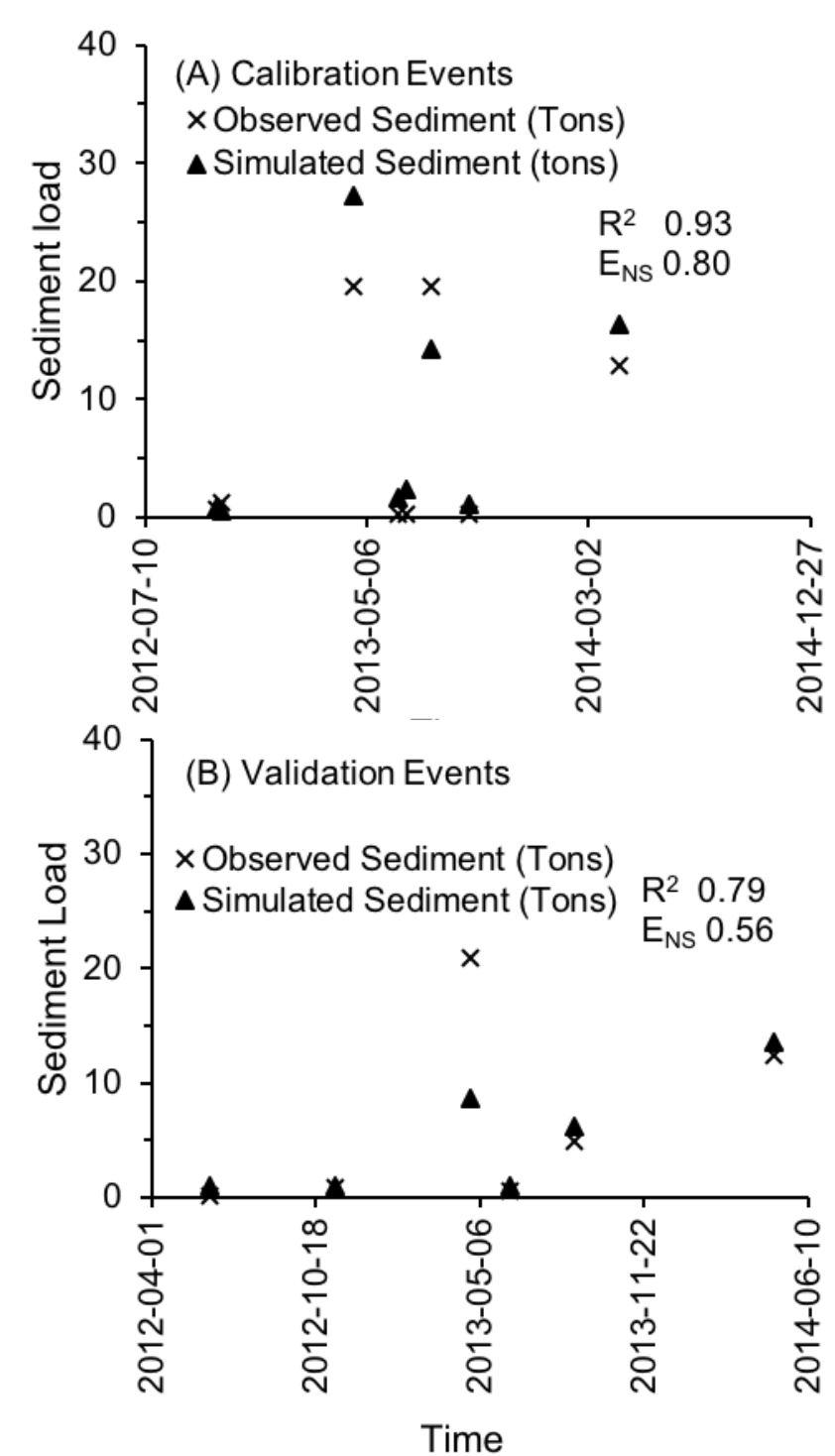

Fig. 6. Events for calibration (A), and validation (B) for sediment loads. for calibration events, with decent statistical parameters (Nash-Sutcliffe efficiencies) as categorized in Table 6. Positive values are generally considered to be acceptable (Safari et al., 2012; Memarian et al., 2013) with values above 0.5 being good. The best performance is for 18 April 2013, which corresponds to spring season characterized by wet soil condition with no crops on the field. Also, the model estimated peak flow very closely resembles the observed data for the event 18 April 2013. The model fit for the event 12 June 2012 is also good, but it is just acceptable for 12 June 2013. Also, Table 6 shows simulated and observed direct runoff for validation events, along with peak flow. The best performance is observed for the event on 12 April 2014, for flow ( $\left.E_{N S}=0.68\right)$. The performance of the model for the event 30 August 2013 is just acceptable for flow $\left(E_{N S}=0.48\right)$. It is not possible to assert that the calibrated parameters are optimal since calibration was carried out manually rather than automated.

Figure 4 shows the observed and computed hydrographs for calibration events. The model performs quite well for calibration events, with acceptable Nash-Sutcliffe efficiencies especially for 18 April 2013 and 12 June 2013 storm events. Model simulated values underestimated peak flow for 18 April 2013 event. However, the model overestimated peak flow for 12 June 2012 and 12 June 2013 storm event. Also, Figure 5 shows simulated hydrographs for validation events, along with observed data. The best performance is observed for the event on 12 April 2014, where both the peak flow and direct runoff is simulated fairly well.

Sediment Observed and simulated sediment load for eight and seven events respectively, at the watershed outlet (Fig. 1) were used for $\mathrm{K} 2$ calibration and validation. The parameters calibrated and their final values are shown in Table 5. Graphical comparison of sediment load for the calibration period (Fig. 6a) and statistical parameters, with $\mathrm{R}^{2} 0.93$ and $\mathrm{E}_{\mathrm{NS}} 0.80$, suggest that the sediment loads were adequately simulated by the K2 model. The observed average sediment load of 6.84 tons (Table 4) was slightly lower than the K2 simulated average sediment load of 8.02 tons over the entire calibration events (14 October $2012-12$ April 2014). Further, Table 6 indicated no significant over-

Table 8. Manning's n for various drainage network/drainage pattern (DNDP).

\begin{tabular}{lrrrr}
\hline & \multicolumn{4}{c}{ 2yr-24 hour (Precipitation = 59.9 mm) } \\
& DNDP_N & DNDP_M (same $\mathrm{n}=0.1)$ & DNDP_MV (n=0.15) & DNDP_HV (n=0.2) \\
\hline $\mathrm{Q}_{\mathrm{p}}\left(\mathrm{m}^{3} / \mathrm{s}\right)$ & 5.51 & 6.39 & 6.02 & 5.62 \\
Runoff $\left(\mathrm{m}^{3}\right)$ & 41503.87 & 45596.29 & 43387.58 & 42168.83 \\
Sediment load (Kg) & 25238.08 & 32344.45 & 29592.45 & 27680.73 \\
\hline
\end{tabular}




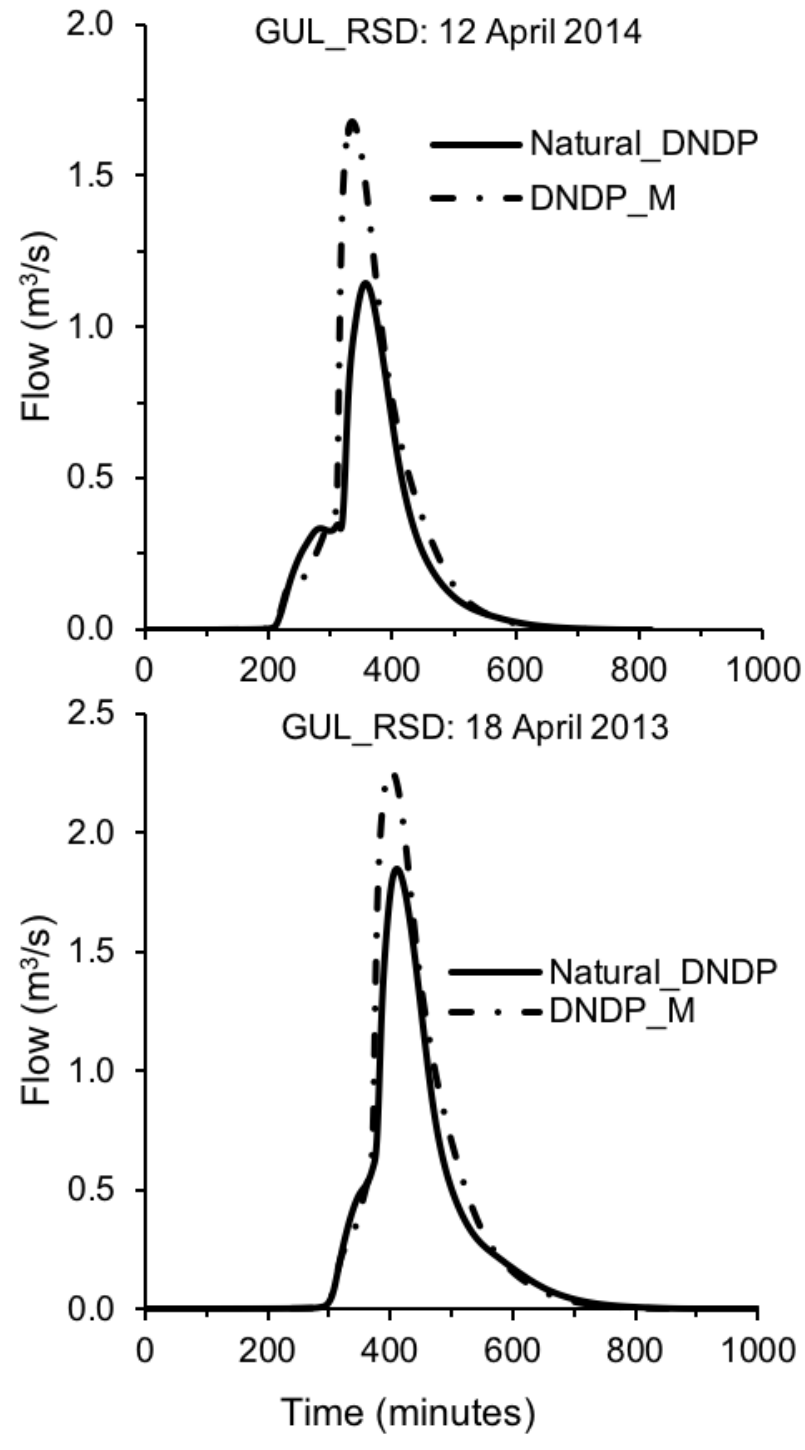

Fig. 7. Simulated hydrographs with KINEROS-2 for post-validation events for DNDP_M scenario.

prediction or underprediction of flow during this simulation period.

Graphical comparison of sediment loads for the validation period (Fig. 6b) and statistical parameters, with $\mathrm{R}^{2} 0.79$ and $E_{\mathrm{NS}} 0.56$; suggest that the sediment loads were adequately simulated by the K2 model. The estimated average sediment load of 6.63 tons was about the same as the predicted sediment load of 5.26 tons over the entire validation period. Since total sediment loads predictions used for post-validation analysis (changed DNDP) were very good, the K2 model was considered to be adequately describing the hydrology of the study watershed.

\section{Post validation}

In this section, the calibrated/validated K2 model was further tested for its capabilities in predicting effects of changes in DNDP on flow and sediment loads. Combination of landuse and soils for the Gully Creek watershed remained the same for both DNDP. Only the water routing network was different under the scenario considered for modified DNDP. Further, a storm event of high intensity could suddenly yield a huge quantity of runoff in a brief period. Henceforth, while analyzing the performance of K2 model for RSD, analysis pertaining to extreme rainfall patterns is of paramount importance. Therefore, a scenario analysis is investigated where the flow is routing for extreme events and its performance assessed at the GUL_RSD outlet. Event with a return period of 2-year with a 24-hour storm duration is selected for analysis. Comparison of the model simulations for flow is presented in the section below.

Flow-DNDP_M (road-side ditches with the same manning's $\overline{\mathbf{n}}$ ) In this scenario, simulated flow values obtained from the model, (DNDP M: with the same Manning's ' $n$ ' as DNDP_N for RSD) were compared with the simulated hydrograph procured under the DNDP_N at the GUL_RSD outlet (Fig. 7). Unaltered Manning's n value of 0.1 estimated during the model calibration was used in this scenario for the channel representing the RSD in this scenario (Table 7). As mentioned in the section above, 12 April 2014 and 18 April 2013 storm events were considered for estimating the model's performance under this scenario analysis during the post-validation phase. Graphical representation of hydrograph for the 18 April 2013 event reveals that the GUL_RSD outlet flows to a maximum of $2.26 \mathrm{~m}^{3} / \mathrm{s}$ and $1.85 \mathrm{~m}^{3} / \mathrm{s}$ for the DNDP_M and the DNDP_N respectively (Fig. 7). Likewise, the volume of direct runoff escalates from $13382.13 \mathrm{~m}^{3}$ to $16010.77 \mathrm{~m}^{3}$ under the revised DNDP. Furthermore, storm event for 12 April 2014 is drained to the GUL_RSD outlet with a peak flow of 1.68 $\mathrm{m}^{3} / \mathrm{s}$ for the altered DNDP_M. Also, Fig. 7 shows that there is a considerable increase in the flow of water routed, with the volume of direct runoff increasing to $10994.35 \mathrm{~m}^{3}$ compared with $8367.52 \mathrm{~m}^{3}$ under the DNDP_N.

Henceforth, it could be concluded that the amount of water routed to the GUL_RSD outlet increases considerably under the DNDP_M. Although this drainage network is convenient for routing water from tile drains etc. to the downstream ecosystems (streams/creeks), it substantially increases the quantity of water routed downstream. Therefore, it is recommended to make certain modifications in the DNDP $M$ to reduce the quantity of water routed to the watershed outlet, thereby minimizing their adverse effect upon downstream water quantity and sediment yield. Flow-DNDP MV (road-side ditches lined with medium vegetation) $\bar{A}$ scenario where road-side ditches are lined with medium vegetation (DNDP_MV) was also considered. For this exercise, manning's $n$ was changed to 0.15 for the channel representing the road-side ditch (Table 7). Simulated flow values obtained from the model for DNDP_MV were compared with the simulated hydrograph procured for the DNDP_N at the GUL_RSD outlet (Fig. 8). Similar to the earlier scenario, 18 April 2013, and 12 April 2014 storm events were again considered for analysis.

Graphical representation of hydrographs for the 18 April 2013 event reveals that the GUL_RSD outlet flows to a maximum of $2.14 \mathrm{~m}^{3} / \mathrm{s}$ and $1.84 \mathrm{~m}^{3} / \mathrm{s}$ for the DNDP_MV and the DNDP_N respectively (Fig. 8). However, considering DNDP_ $\mathrm{N}$ as a baseline, the percentage increase 

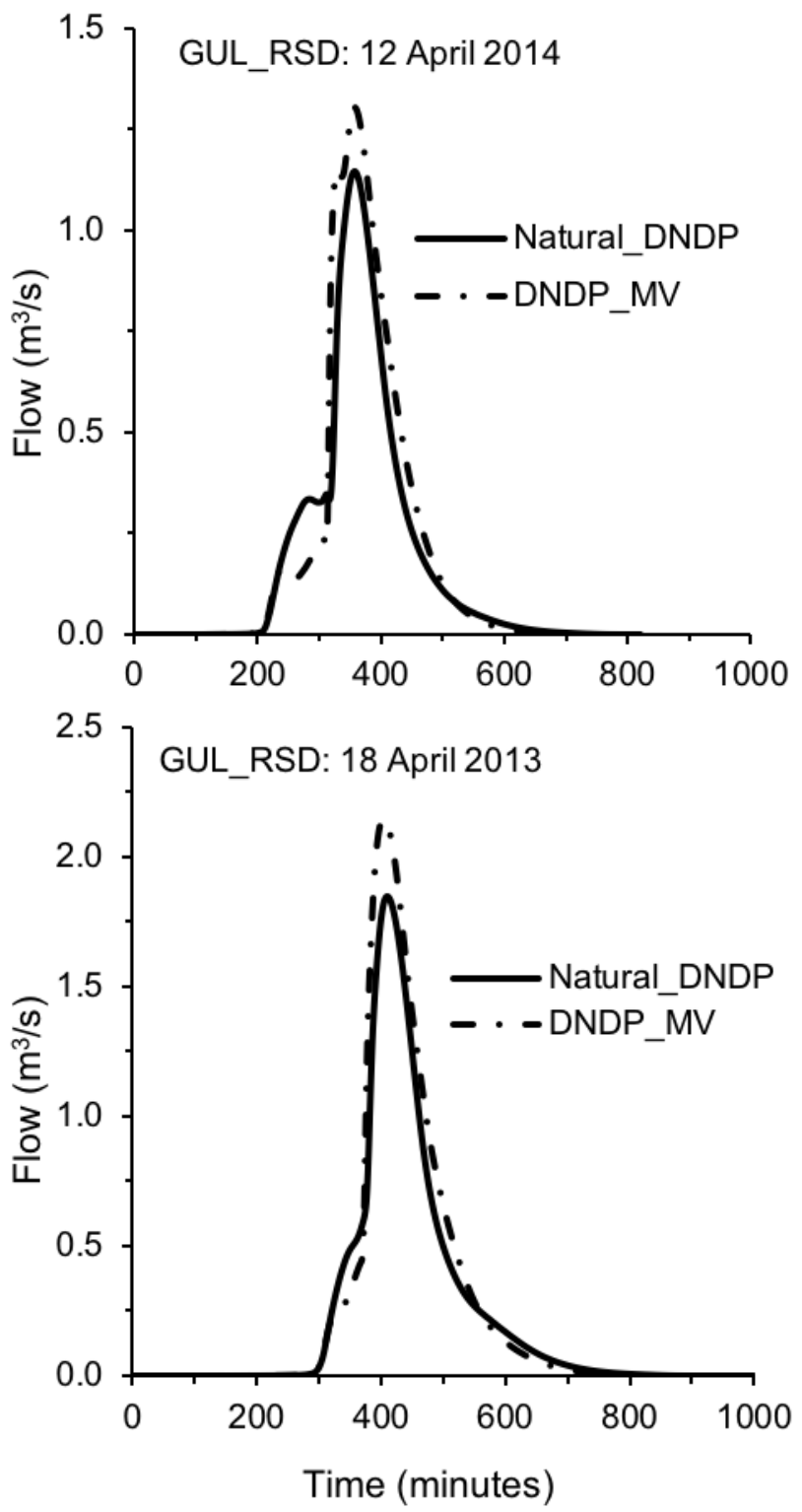

Fig. 8. Simulated hydrographs with KINEROS-2 for post-validation events for DNDP_MV scenario.

in peak flow reduces from $22.16 \%$ to $15.67 \%$. Likewise, the percentage increase in direct runoff volume reduces from $22.16 \%$ to $15.67 \%$ under this revised scenario. However, compared to DNDP_N; the direct runoff volume is still higher (Table 7). Furthermore, the 12 April 2014 storm event drains to the GUL_RSD outlet with a peak flow of $1.31 \mathrm{~m}^{3} / \mathrm{s}$. Also, Fig. 8 reveals that the volume of water routed is still considerably higher than DNDP_N. However, compared with DNDP $M$ the percentage increase in peak flow diminishes from $4 \overline{7} .36 \%$ to $14.91 \%$ keeping DNDP_N as the baseline. Similarly, compared with DNDP_M, the percentage increase in direct runoff volume reduces from $31.34 \%$ to $13.03 \%$ respectively (Table 7 ).

Flow-DNDP_HV (road-side ditches lined with thick vegetation) In this scenario, flow is routed through the modified DNDP_HV considering a lining of thick vegetation over the drainage ditches. Henceforth manning's $\mathrm{n}$ is marginally increased $(0.2)$ for the RSD considered (Table 7). A procedure similar to the above-mentioned scenario's is considered, where model simulated flow routed for the DNDP HV scenario is compared DNDP MV, DNDP $M$ and DNDP $\mathrm{N}$ at the GUL RSD outlet for 12 April 2014, and 18 April 2013 storm events respectively (Fig. 9). Model simulated hydrograph at GUL_RSD for the 12 April 2014 event (Fig. 9) reveals that percentage increase in peak flow, reduces to $1.75 \%$ for this scenario, which is substantially lower than $47.36 \%$ for DNDP_M, $14.91 \%$ for DNDP_MV compared to the ${ }_{\text {DNDP_N }}^{-}$baseline respectively ${ }^{-}$(Table 7). Also, the percentage increase in direct runoff volume reduces to 8.67 \% compared with $31.39 \%$ for DNDP_M and DNDP_MV respectively (Table 7).

Similarly, flow simulated at the GUL_RSD outlet for 18 April 2013 storm reveals a peak flow of $1.83 \mathrm{~m}^{3} / \mathrm{s}$ for the DNDP_HV which is significantly less than the peak flow procured under DNDP_MV drainage scenario, a reduction from $15.67 \%$ to $-1.08 \%$ when compared with the DNDP_N scenario (Table 7 and Fig. 9). Subsequently, Table 7 demonstrates a modest increase in the quantity of direct runoff simulated; a percentage increase of $1.55 \%$ compared with DNDP_N. However, a considerable reduction in direct runoff volume is observed when compared to DNDP_M $(19.64 \%)$ and DNDP MV (11.29\%) respectively. Therefore, since the flow simulated at the GUL_RSD outlet decreases for DNDP_HV compared with DNDP_M and DNDP_MV, it is recommended to line the road-side ditches with a heavy vegetation like thick grass-cover. It would increase the manning's $n$ value which would further reduce the quantity of water routed.

Sediment-DNDP_M (road-side ditches with the same manning's n) Upon successful calibration and validation of the model for flow (peak flow and direct runoff) and sediment, the K2 model was run for 12 April 2014, and 18 April 2013 storm events under the modified DNDP scenario. Manning's $n$ was kept unchanged to 0.1 for the channel representing the RSD under the modified DNDP (Table 7). Further results were compared at the GUL_RSD outlet. The results indicate that DNDP-M increased sediment loads by 26.97 , and $18.32 \%$ for 12 -Apr-14, and 18-Apr-13 storm events respectively. Table 7 shows detailed sediment loads at the GUL_RSD outlet. Results clearly demonstrate that the change in DNDP significantly increases the amount of sediment loads routed.

Sediment-DNDP_MV (road-side ditches lined with medium vegetation) In this scenario sediment routed under modified DNDP_MV; where the road-side ditches are lined with medium vegetation is considered. Manning's n representing the RSD was altered to 0.15 in this scenario. Sediment loads increased by 18.83 , and $13.34 \%$ for 12 -Apr14 , and 18-Apr-13 storm events respectively compared with the DNDP N. However, when compared with the DNDP_M, the sediment loads reduced (Table 7).

Sediment-DNDP_HV (road-side ditches lined with thick Vegetation) Under this scenario analysis, the sediment load routed decreases further. Increase in Manning's n to 0.2 reduces flow and sediment load for 12-Apr-14 storm event (Table 7). Compared to DNDP_M (26.95\%) and 

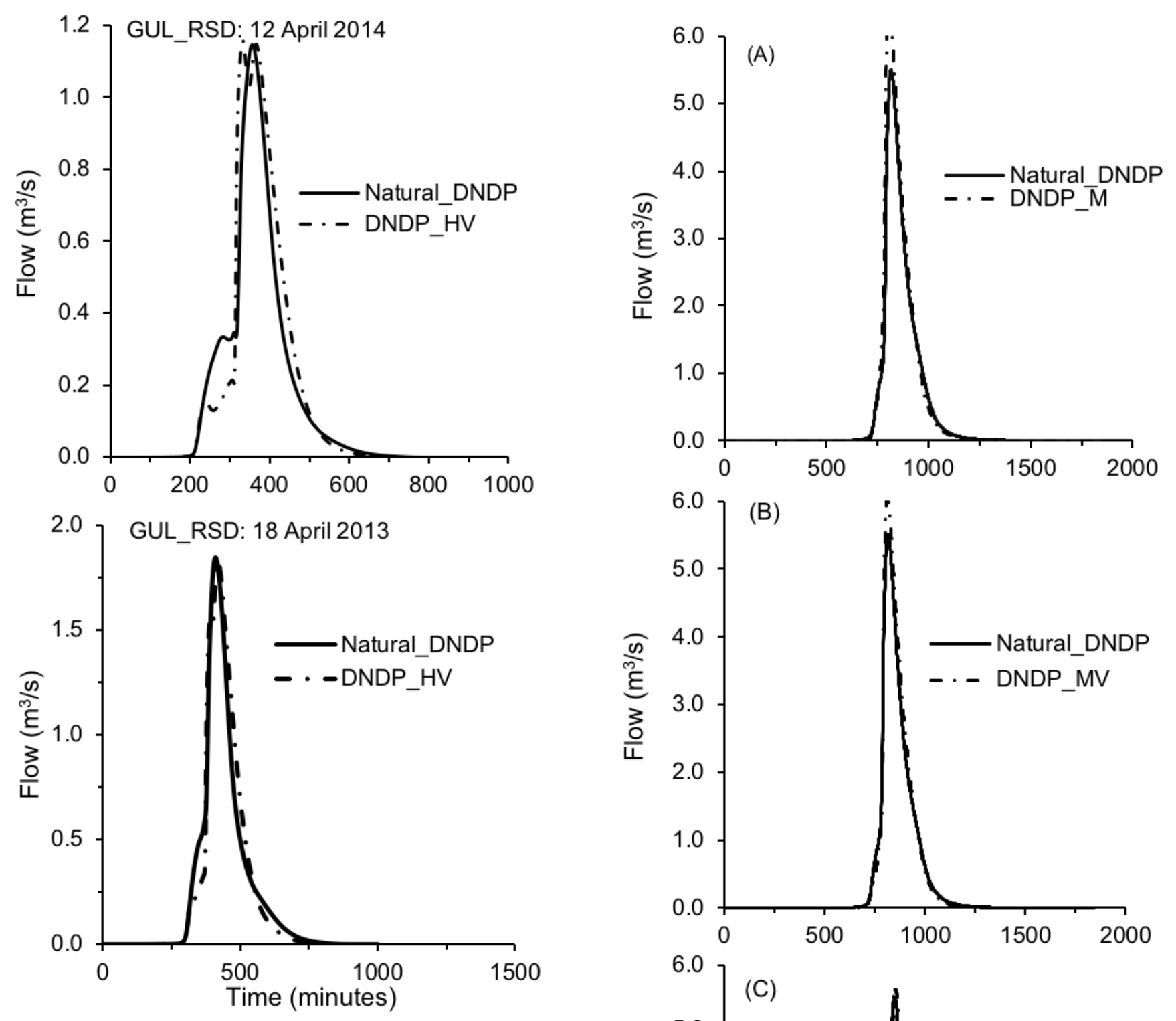

Fig. 9. Simulated hydrographs with KINEROS-2 for post-validation events for DNDP_HV scenario.

DNDP_MV (18.84\%), the percentage increase in sediment load reduces to $8.6 \%$ considering the DNDP $\mathrm{N}$ as the benchmark. However, the sediment loads are still higher compared with the sediment loads procured under DNDP_N. Similar results are obtained for 18-Apr-13 storm event where an increase in sediment load reduced to $4.18 \%$ compared with $18.33 \%$ and $13.33 \%$ for DNDP_M and DNDP MV respectively. Therefore, since the amount of sediment load simulated at the GUL_RSD outlet decreases further for the DNDP_HV compared with the DNDP_MV, it is recommended to line the RSD with a thick vegetation like grass-cover since it increases manning's n value which would reduce the quantity of water and sediment routed at the GUL_RSD outlet.

2-Year 24-Hour Design storm In this scenario model simulated flow routed for the DNDP_M, DNDP_MV and
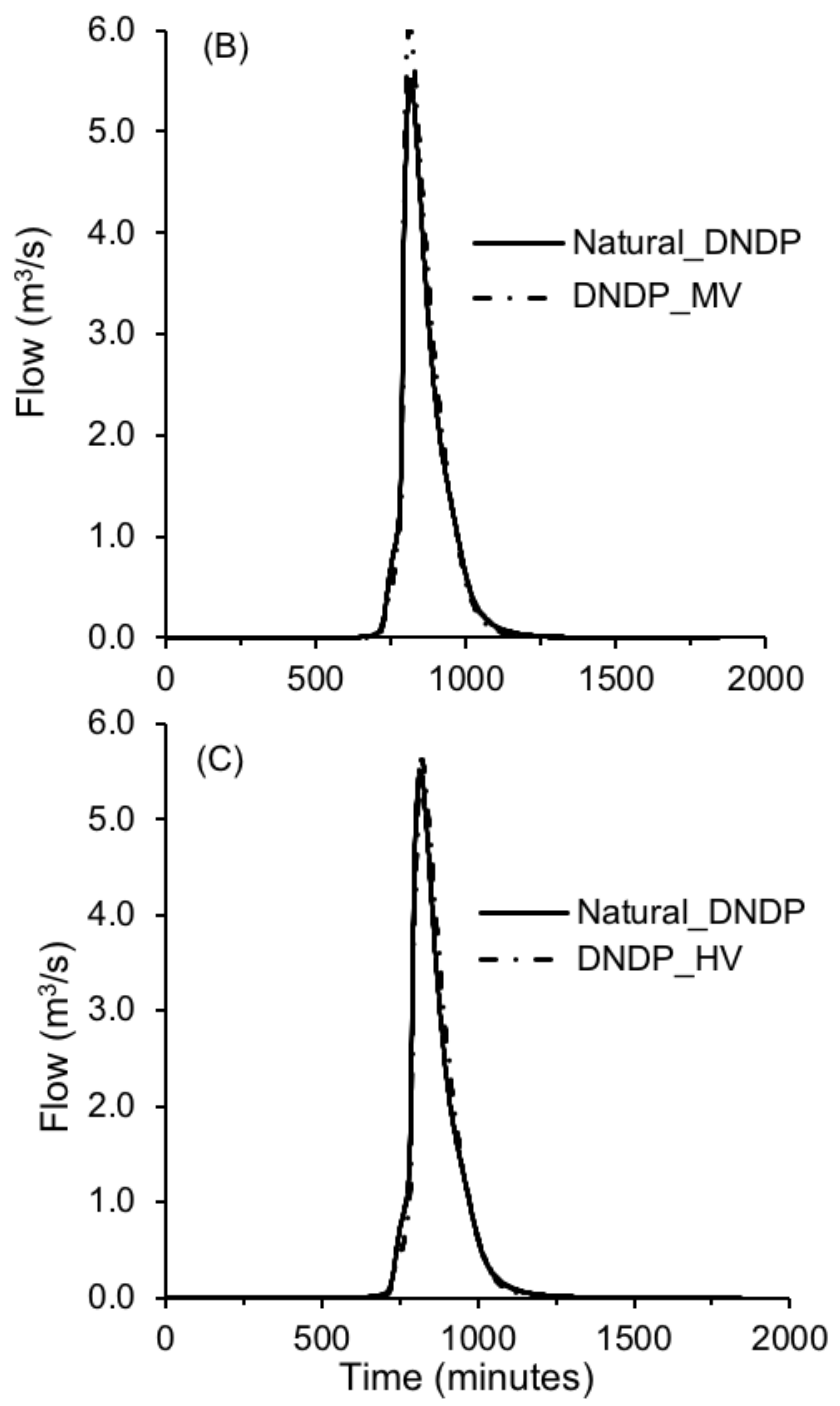

Fig. 10. Simulated hydrographs (A) DNDP_M (B) DNDP_MV and (C) DNDP_HV for 2-year-24hour design storm. 
DNDP HV scenarios at the GUL_RSD outlet are compared for a synthetic 2-year 24-hour design storm (Table 8, Fig. 10). Also, model-simulated hydrographs for the design storm (Fig. 10) reveals that percentage increase in peak flow is $15.97 \%, 9.25 \%$, and $1.99 \%$ respectively for DNDP $M$, DNDP_MV, and DNDP_HV scenarios compared with DNDP_N (Table 8). Furthermore, the percentage increase in direct runoff volume is $9.86 \%, 4.53 \%$, and $1.6 \%$ respectively for DNDP_M, DNDP_MV and DNDP_HV scenarios (Table 8). Sediment routed under these scenarios indicate that RSD lined with thick vegetation cover (DNDP_HV) is successful in mitigating the sediment loads and getting the values close to the natural conduction (DNDP N) (Table 8).

\section{CONCLUSIONS}

Watershed models are mostly calibrated and validated for a study area with the existing natural DNDP. However, in modern times due to urbanization and altercation of drainage network due to tile drains, there may be a significant change in the DNDP of watersheds. The main objective of this paper was to explore the performance of the KINEROS 2(K2) model in predicting water quantity and sediment yield in response to alterations in DNDP within an environmentally-sensitive watershed in Ontario, Canada. Results demonstrated that the model was able to simulate flow (peak flow and direct runoff) and sediment loads satisfactorily for both calibration and validation events. The calibrated model then was fed with a modified DNDP. The model-produced outputs for peak flow, direct runoff, and sediment yield were compared for two rainfall events (12 April 2014 and 18 April 2013) and a synthetic design storm (2year-24hour) at the GUL_RSD outlet under three distinct DNDP (natural vegetation, medium, and thick vegetation). The results procured for the altered DNDP scenario were as expected. The following observations and conclusions are drawn:

1. K2 performed well for DNDP_N, both for the calibration and validation events. Also, for altered DNDP, keeping the natural vegetation lining on the RSD (DNDP_M) the model-simulated peak flow, direct runoff and sediment yield increased as expected for the for post-validation events.

2. Further, when RSD were lined with a thicker vegetation (DNDP_MV and DNDP_HV), a reduction in peak flow, direct runoff, and sediment yield was observed compared to DNDP_M.

3. A DNDP with thick vegetation cover, which would have a higher value for manning's $\mathrm{n}$, is more efficient in reducing the peak flow, direct runoff volume and sediment loads, both for the natural rainfall events and the synthetic design storm (2year-24-hour).

In summary, this study showed that $\mathrm{K} 2$ could be a useful model in simulating flow and sediment within watersheds undergoing severe alterations in their drainage pattern due to development or implementation of specific watershed management plans. However, it should be noted that this is just an isolated study conducted in a cold region. Similar studies under different physiographic and climatic regions can further reinforce conclusions of this study.

\section{ACKNOWLEGEMENT}

The authors acknowledge the financial support from Ontario Ministry of Agriculture, Food and Rural Affairs (OMAFRA), Natural Sciences and Engineering Research Council (NSERC), and the University of Guelph for this study.

\section{REFERENCES}

Acde, M. B., L. Montarcih and L. Cef. 2017. Application of the Kineros model for predicting the effect of land use on the surface run-off Case study in Brantas subwatershed, Klojen District, Malang City, East Java Province of Indonesia. Journal of Water and Land Development 35 (X-XII): 3-9. https://doi.org/10.1515/jwld-2017-0062

Ahiablame, L. M., I. Chaubey, D.R. Smith and B.A. Engel. 2011. Effect of tile effluent on nutrient concentration and retention efficiency in agricultural drainage ditches. Agricultural Water Management 98(8): 1271-1279. https://doi.org/10.1016/j.agwat.2011.03.002

Ahiablame, L., I. Chaubey and D. Smith. 2010. Nutrient Content at the Sediment-Water Interface of Tile-Fed Agricultural Drainage Ditches. Water (Switzerland) 2(3): 411-428. https://doi.org/10.3390/w2030411

Alexander, R. B., R.A. Smith, G.E. Schwarz, E.W Boyer, J.V. Nolan and J.W. Brakebill. 2008. Differences in Phosphorus and Nitrogen Delivery to the Gulf of Mexico from the Mississippi River Basin. Environmental Science and Technology 42(3): 822-830. https://doi: 10.1021/es0716103

Birgand, F., R.W. Skaggs, G.M. Chescheir and J.W. Gilliam. 2007. Nitrogen removal in streams of agricultural catchments - A literature review. Critical Reviews in Environmental Science and Technology 37(5): 381-487. https://doi.org/10.1080/10643380600966426

Borah, D. K. and M. Bera. 2004. Watershed-scale Hydrologic and Nonpoint-Source pollution Models: Review of Applications. Transactions of the ASAE 47(3): 789-803.

Borah, D. K., J.G. Arnold, M. Bera, E.C. Krug and X.Z. Liang. 2007. Storm Event and Continuous Hydrologic Modeling for Comprehensive and Efficient Watershed Simulations. Journal of Hydrologic Engineering 12(6): 605-616. https://doi.org/10.1061/(ASCE)10840699(2007)12:6(605)

Buchanan, B., Z.M. Easton, R.L. Schneider and M.T. Walter. 2011. Incorporating variable source area hydrology into a spatially distributed direct runoff model. Journal of the American Water Resources Association 48(1): 43-60.

Buchanan, B., Z.M. Easton, R.L. Schneider and M.T. Walter. 2013. Modeling the hydrologic effects of roadside ditch networks on receiving waters. Journal of Hydrology 486: 293-305.

https://doi.org/10.1016/j.jhydrol.2013.01.040

Cuo, L., T.W. Giambelluca, A.D. Ziegler and M.A. Nullet. 2006. Use of the Distributed Hydrology Soil Vegetation Model to Study Road Effects on Hydrological Processes 
in Pang Khum Experimental Watershed, northern Thailand. Forest Ecology and Management 224: 81-94. https://doi.org/10.1016/j.foreco.2005.12.009

Eckhardt, K. and J.G. Arnold. 2001. Automatic calibration of a distributed catchment model. Journal of Hydrology 251(1-2): 103-109. https://doi.org/10.1016/S0022-1694(01)00429-2

Falbo, K., R.L. Scheider, D.H. Buckley, M.T. Walter, P.W. Bergholz and B.P. Buchanan. 2013. Roadside ditches as conduits of fecal indicator organisms and sediment: Implications for water quality management. Journal of Environmental Management 128: 1050-1059. https://doi.org/10.1016/j.jenvman.2013.05.021

Gentry, L. E., M.B. David, T.V. Royer, C.A. Mitchell and K.M. Starks. 2007. Phosphorus Transport Pathways to Streams in Tile-Drained Agricultural Watersheds. Journal of Environment Quality 36(2): 408-415. https://doi.org/10.2134/jeq2006.0098

Golmohammadi, G., R. Rudra, T. Dickinson, P. Goel and M. Veliz. 2017. Predicting the temporal variation of flow contributing areas using SWAT. Journal of Hydrology 547: 375-386. https://doi.org/10.1016/j.jhydrol.2017.02.008

Golmohammadi, G., S.O. Prasher, A. Madani, R.P. Rudra and M.A. Youssef. 2016. SWATDRAIN, a new model to simulate the hydrology of agricultural Lands, model development and evaluation. Biosystems Engineering 141: 31-47. https://doi.org/10.1016/j.biosystemseng.2015.11.003

Iseyemi, O. O., J.L. Farris, M.T. Moore and S.eun. Choi. 2016. Nutrient Mitigation Efficiency in Agricultural Drainage Ditches: An Influence of Landscape Management. Bulletin of Environmental Contamination and Toxicology 96(6): 750-756. https://doi.org/10.1007/s00128-016-1783-x

Kalin, L. and M.M. Hantush. 2006a. Comparative assessment of two distributed watershed models with application to a small watershed. Hydrological Processes 20: 2285-2307. https://doi.org/10.1002/hyp.6063

Kalin, L. and M.M. Hantush. 2006b. Hydrologic Modeling of an Eastern Pennsylvania Watershed with NEXRAD and Rain Gauge Data. Journal of Hydrologic Engineering 11(6): 555-569. https://doi.org/ 10.1061/(ASCE)1084-0699(2006)

Kleinman, P. J. A., A.L. Allen, B.A. Needelman, A.N. Sharpley, P.A. Vadas, L.S. Saporito, G.J. Folmar and R.B. Bryant. 2007. Dynamics of phosphorus transfers from heavily manured Coastal Plain soils to drainage ditches. Journal of Soil and Water Conservation 62(4): 225-235.

Kyoung, J. L., B.A. Engel, Z. Tang, J. Choi, K.S. Kim, S. Muthukrishnan and D. Tripathy. 2005. Automated Web GIS based hydrograph analysis tool, WHAT. Journal of the American Water Resources Association 41(6): 1407-1416. 1688.2005.tb03808.x

Lyne, V. and M. Hollick. 1979. Stochastic time variable rainfall-runoff modeling. Proceedings of the Hydrology and Water Resources Symposium, 89-92. Perth, Australia. September 10-12.
Ma, L., L.R. Ahuja, J.C. Ascough, M.J. Shaffer, K.W. Rojas, R.W. Malone and M.R. Cameira. 2001. Integrating system modeling with field research in agriculture: applications of the Root Zone Water Quality Model (RZWQM). Advances in Agronomy 71: 233-292. https://doi.org/10.1016/S0065-2113(01)71016-4

Marion, A., V. Nikora, S. Puijalon, T. Bouma, K. Koll, F. Ballio, S. Tait, M. Zaramella, A. Sukhodolov, M. O'Hare, G. Wharton, J. Aberle, M. Tregnaghi, P. Davies, H. Nepf, G. Parker and B. Statzner. 2014. Aquatic interfaces: A hydrodynamic and ecological perspective. Journal of Hydraulic Research 52(6): 744-758. https://doi.org/10.1080/00221686.2014.968887

Memarian, H., S.K. Balasundram, J.B. Talib, C. T. B. Sung, A.M. Sood and K.C. Abbaspour. 2013. KINEROS2 application for land use/cover change impact analysis at the Hulu Langat Basin, Malaysia. Water and Environment Journal 27(4): 549-560. https://doi.org/10.1111/wej.12002

Moriasi, D.N., M.W. Gitau, N. Pai and P. Daggupati. 2015. Hydrologic and Water Quality Models: Performance Measures and Evaluation Criteria. Transactions of the ASABE 58(6): 1763-1785. https://doi.org/10.13031/trans.58.10715

Moriasi, D. N., C.G. Rossi, J.G. Arnold and M.D. Tomer. 2012. Evaluating hydrology of the Soil and Water Assessment Tool (SWAT) with new tile drain equations. Journal of Soil and Water Conservation 67(6): 513-524. https://doi.org/10.2489/jswc.67.6.513

Nash, J.E. and J.V. Sutcliffe. 1970. River flow forecasting through conceptual models: Part I. A discussion of principles. Journal of Hydrology 10(3): 282-290. https://doi.org/10.1016/0022-1694(70)90255-6

Needelman, B.A., P.J.A. Kleinman, J.S. Strock and A.L. Allen. 2007. Improved Management of Agricultural Drainage Ditches for Water Quality Protection: An overview. Journal of Soil and Water Conservation62(4): 171-177.

Nguyen, H. Q., J. Degener and M. Kappas. 2016. Flash flooding prediction in regions of northern Vietnam using the KINEROS2 model. Hydrology Research 47(5): 1038-1052. https://doi.org/10.2166/nh.2015.125

Park, Y. S., B.A. Engel, J. Frankenberger and H. Hwang. 2015. A web-based tool to estimate pollutant loading using LOADEST. Water (Switzerland) 7(9): 48584868. https://doi.org/10.3390/w7094858

Pinay, G., S. Peiffer, J.R. De Dreuzy, S. Krause, D.M. Hannah, J.H. Fleckenstein, M. Sebilo, K. Bishop and L. Hubert-Moy. 2015. Upscaling Nitrogen Removal Capacity from Local Hotspots to Low Stream Orders' Drainage Basins. Ecosystems 18(6): 1101-1120. https://doi.org/10.1007/s10021-015-9878-5

Runkel, R.L., C.G. Crawford and T.A. Cohn. 2004. Load Estimator (LOADEST): A FORTRAN program for estimating constituent loads in streams and rivers. 4: A5.

Safari, A., F. De Smedt and F. Moreda. 2012. WetSpa model application in the Distributed Model Intercomparison Project (DMIP2). Journal of Hydrology 418-419: 78-89.

https://doi.org/10.1016/j.jhydrol.2009.04.001 
Semmens, D., D. Goodrich, C. Unkrich, R. Smith, D. Woolhiser and S. Miller. 2007. KINEROS2 and the AGWA modeling Framework. Hydrological Modelling in Arid and Semi-Arid Areas, International Hydrology Series. Cambridge: Cambridge University Press. https://doi.org/10.1017/CBO9780511535734.006

Sloan, B. P., R. Mantilla, M. Fonley and N.B. Basu. 2017. Hydrologic impacts of subsurface drainage from the field to watershed scale. Hydrological Processes 31(17): 3017-3028. https://doi.org/10.1002/hyp.11218

Smith, D. R. 2009. Assessment of in-stream phosphorus dynamics in agricultural drainage ditches. Science of the Total Environment 407(12): 3883-3889. https://doi.org/10.1016/j.scitotenv.2009.02.038

Smith, D. R. and E.A. Pappas. 2007. Effect of ditch dredging on the fate of nutrients in deep drainage ditches of the Midwestern United States. Journal of Soil and Water Conservation 62(4): 252-261.

Smith, D. R., B.E. Haggard, E.A. Warnemuende and C. Huang. 2005. Sediment phosphorus dynamics for three tile fed drainage ditches in Northeast Indiana. Agricultural Water Management 71(1): 19-32. https://doi.org/10.1016/j.agwat.2004.07.006

Smith, R. E., D.C. Goodrich and C.L. Unkrich. 1999. Simulation of selected events on the Catsop catchment by KINEROS2 A report for the GCTE conference on catchment scale erosion models, 457-475.
Smith, R. E., D.C. Goodrich and J.N. Quinton. 1995. Dynamic, distributed simulation of watershed erosion: The KINEROS2 and EUROSEM models. Journal of Soil and Water Conservation 50(5): 517-520.

Soana, E., R. Balestrini, F. Vincenzi, M. Bartoli and G. Castaldelli. 2017. Mitigation of nitrogen pollution in vegetated ditches fed by nitrate-rich spring waters. Agriculture, Ecosystems and Environment 243: 74-82. https://doi.org/10.1016/j.agee.2017.04.004

Strock, J. S., C.J. Dell and J.P. Schmidt. 2007. Managing natural processes in drainage ditches for non-point source nitrogen control. Journal of Soil and Water Conservation 62(4): 188-196.

Surfleet, C. G., A.E. Skaugset and J.J. McDonnell. 2010. Uncertainty assessment of forest road modeling with the Distributed Hydrology Soil Vegetation Model (DHSVM). Canadian Journal of Forest Research 40(7): 1397-1409. https://doi.org/10.1139/X10-079

Woolhiser, D.A., R.E. Smith and E.C. Goodrich. 1990. A Kinematic Runoff and Erosion Model: Documentation and User Manual, U.S. Department of Agriculture. Agricultural Research Service, ARS-77. 130 Pp, 1990.

Yang, W., Y. Liu, J. Simmons, A. Oginskyy and K. McKague. 2013. SWAT Modelling of Agricultural BMPs and Analysis of BMP Cost Effectiveness in the Gully Creek Watershed. University of Guelph, Guelph, Ontario. xi. 